$\begin{array}{ll}\text { Volume } & : 05 \\ \text { Nomor } & : 02 \\ \text { Bulan } & : \text { Mei } \\ \text { Tahun } & : 2019 \\ \text { http } & : / / \text { ejurnal.pps.ung.ac.id/index.php/AKSARA/index }\end{array}$

\title{
UPAYA PENINGKATAN KINERJA GURU DALAM PROSES PEMBELAJARAN MELALUI SUPERVISI KLINIS PENGAWAS DI SD BINAAN WILAYAH KECAMATAN NAPABALANO KABUPATEN MUNA TAHUN PELAJARAN 2013/2014
}

\author{
La Omi \\ Pengawas Dinas Pendidikan Kabupaten Muna \\ laomi@gmail.com \\ Received: 29 Februari 2019; Revised: 12 April 2019; Accepted: 15 April 2019
}

\begin{abstract}
ABSTRAK
Tujuan dari penelitian tindakan ini adalah untuk mengetahui sejauh mana peningkatan kinerja guru dalam proses pembelajaran melalui supervisi klinis Pengawas di SD Binaan Wilayah Kecamatan Napabalano Tahun pelajaran 2013/2014. Dalam penelitian tindakan ini dilakukan dalam 2 siklus, dari hasil tindakan yang dilakukan terbukti dapat meningkatkan kinerja guru dengan mencapai standar ideal. Dari 67,40\% pada Siklus 1, dapat meningkat menjadi $86,50 \%$ pada siklus II.Hasil penelitian tindakan ini menunjukkan bahwa pembinaan Pengawas melalui supervisi klinis efektif untuk meningkatkan kinerja guru dalam proses pembelajaran di SD Binaan Wilayah Kecamatan Napabalano Kabupaten Muna.
\end{abstract}

Kata Kunci : Kinerja Guru, Supervisi Klinis Pengawas.

\section{PENDAHULUAN}

Peningkatan mutu pendidikan di Indonesia terus diupayakan oleh pemerintah agar pendidikan di negara kita tidak ketinggalan dengan kemajuan pendidikan yang telah dicapai oleh negara maju. Berbagai upaya yang dilakukan antara lain melalui perubahan undangundang pendidikan dari sistem sentralisasi ke desentralisasi, kurikulum, sarana prasarana pendidikan, maupun tenaga kependidikan/guru, baik yang dilakukan melalui pemberian beasiswa untuk melanjutkan ke jenjang pendidikan yang lebih tinggi, maupun melalui pelatihan/workshop yang diadakan di tingkat Kabupaten, Provinsi, maupun tingkat Nasional. Namun kenyataannya di lapangan mutu pendidikan masih jauh dari yang diharapkan. Hal ini dipengaruhi oleh sejumlah faktor diantaranya: mutu pembelajaran yang belum mampu menciptakan proses pembelajaran yang berkualitas. Hasil pendidikan belum didukung oleh sistem pengujian dan penilaian yang melembaga dan independen serta instrumen tujuan yang belum sesuai dengan konsep yang diukur sehingga belum dapat dimonitor secara objektif dan teratur sehingga hasil penilaian pendidikan belum berfungsi sebagai sarana umpan balik karena belum dilakukan secara teratur (Depdiknas, 2003:3).

Operasionalisasi dari sentralisasi ke desentralisasi pendidikan adalah berjalannya manajemen berbasis sekolah, akan tetapi kurikulum sekolah yang terstruktur dan syarat beban menjadikan proses pembelajaran steril terhadap keadaan dan permasalahan yang terjadi di lingkungan yang tidak mungkin bagi guru, kepala sekolah, dan pengelola pendidikan di daerah dilakukan secara inovatif akibatnya sekolah belajar konservatif, kurang fleksibel, dan tidak mudah berubah seiring dengan perubahan jaman. Perubahan-perubahan di atas menuntut berbagai tugas yang harus dikerjakan oleh tenaga kependidikan sesuai dengan peran dan fungsinya masing-masing mulai dari level mikro, yakni tenaga kependidikan di sekolah. Di sekolah terdapat yang paling berperan dan sangat menentukan kualitas pendidikan yakni kepala sekolah dan guru. 


$\begin{array}{ll}\text { Volume } & : 05 \\ \text { Nomor } & : 02 \\ \text { Bulan } & : \text { Mei } \\ \text { Tahun } & : 2019 \\ \text { http } & : \text { //ejurnal.pps.ung.ac.id/index.php/AKSARA/index }\end{array}$

Untuk meningkatkan kemampuan guru dan kepala sekolah dalam menjalankan peran dan fungsinya secara efektif terutama dalam proses belajar di kelas, maka peningkatan mutu pembelajaran perlu dilakukan secara kontinu dan berkelanjutan oleh pengawas di wilayah yang menjadi tanggung jawabnya melalui supervisi akademis, ini sangat diperlukan agar keefektifan dan tujuan pembelajaran di sekolah dapat tercapai.

Hal ini dilakukan karena kelayakan mengajar guru tidak cukup hanya diukur berdasarkan pendidikan formal tetapi juga harus diukur berdasarkan bagaimana kemampuan guru dalam mengajar dan sesi penguasaan materi, menguasai, memilih dan menggunakan metode, media serta evaluasi pembelajaran. Sehubungan dengan hal di atas, Jiyono ( 1987 ) menyimpulkan bahwa kemampuan guru dalam menguasai bahan pelajaran pada umumnya sangat menghawatirkan karena dari sampel guru yang diminta menunjukkan kemampuan menguasai bahan pelajaran $70 \%$ yang kurang menguasai bahan pelajaran, sedangkan $30 \%$ nya hanya menguasai bahan pelajaran.

Dalam penelitian ini penulis mencoba untuk mengkaji dan menggali supervisi (Pengawas) yang berkaitan dengan kemampuan guru dalam proses belajar mengajar, disebabkan oleh: (1). Adanya kecenderungan melemahnya kinerja guru dimana berdasarkan pengalaman penulis menjadi Pengawas yaitu terjadinya guru yang membolos mengajar, guru yang masuk ke kelas yang tidak tepat waktu, guru mengajar tidak mempunyai persiapan mengajar, guru tidak punya absensi siswa, (2) adanya pelaksanaan supervisi yang dilakukan oleh Pengawas belum dilaksanakan dengan sebaik-baiknya kepada guru. Beberapa rekan penulis yang sama-sama menjadi Pengawas mengaku kurang serius dalam melaksanakan fungsinya sebagai supervisor, (3) adanya penurunan kemampuan guru dalam proses pembelajaran di kelas merupakan salah satu penyebab menurunnya nilai UAN siswa di SD Binaan Wilayah Kecamatan Napabalano.

Kurangnya kemampuan guru dalam mengelola pembelajaran di kelas disebabkan oleh ketidakmampuan guru dalam melaksanakan peran dan fungsinya di sekolah.

Menjadi guru yang profesional tidak cukup dengan lamanya mereka menjadi guru, tetapi diperlukan kemampuan mengatasi masalah, mengembangkan dan membuat perencanaan sekolah, akan tetapi guru yang profesional setidaknya ada empat kompetensi yang harus dimiliki oleh seorang guru yaitu ; (1) kompetensi profesional, (2) kompetensi pedagogik, (3) kompetensi keperibadian, dan (4) kompetensi sosial. Oleh karena itu peran Pengawas dalam membina guru di sekolah yang menjadi tanggung jawabnya sangat penting agar mutu pendidikan dapat ditingkatkan.

\section{KAJIAN PUSTAKA \\ Kinerja Guru dan Indikatornya}

Istilah kinerja mengajar guru merupakan kinerja guru dalam meningkatkan kemampuannya melaksanakan pembelajaran di kelas. Kinerja dapat diterjemahkan dalam perfomance atau unjuk kerja, artinya kemampuan yang ditampilkan seseorang terhadap pekerjaannya pada tempat ia bekerja. Kinerja merupakan suatu kinerja yang esensial terhadap keberhasilan suatu pekerjaan. Karena itu suatu kinerja yang efektif bagi setiap individu perli diciptakan sehingga tujuan lembaga dapat tercapai secara optimal.

Menurut Fattah (1996) kinerja diartikan sebagai ungkapan kemajuan yang didasari oleh pengetahuan, sikap, keterampilan dan otivasi dalam menghasilkan suatu pekerjaan. Dengan demikian dapat disimpulkan bahwa kinerja adalah hasil kerja seseorang yang mencerminkan prestasi kerja sebagai ungkapan pengetahuan, sikap dan keterampilan.

Menurut Supriadi (1998) kinerja guru akan menjadi lebih baik, bila seorang guru memiliki lima hal yakni:

1. Memiliki komitmen pada siswa dan proses belajarnya

112 AKSARA Jurnal Ilmu Pendidikan Nonformal 


$\begin{array}{ll}\text { Volume } & : 05 \\ \text { Nomor } & : 02 \\ \text { Bulan } & : \text { Mei } \\ \text { Tahun } & : 2019 \\ \text { http } & : \text { //ejurnal.pps.ung.ac.id/index.php/AKSARA/index }\end{array}$

2. Menguasai secara mendalam bahan mata pelajaran yang akan diajarkan serta cara mengajarnya kepada siswa

3. Bertanggung jawab memantau hasil belajar siswa melalui berbagai cara evaluasi, dan

4. Guru mampu berpikir sistematis tentang apa yang dilakukannya dan belajar serta pengalamannya.

Lebih lanjut Hamalik (2002) kemampuan dasar yang disebut juga kinerja dari seorang guru teridiri dari: (1) kemampuan merencanakan pembelajaran, (2) kemampuan mengelola program belajar mengajar, (3) kemampuan mengelola kelas (4) kemampuan menggunakan media/sumber belajar, (5) kemampuan mengelola interaksi belajar mengajar, (6) mampu melaksanakan evaluasi belajar siswa.

Kinerja guru sangat terkait dengan efektifitas guru dalam melaksanakan fungsinya oleh Medley dalam Depdikbud (1984) dijelaskan bahwa efektifitas guru yaitu: (1) memiliki pribadi kooperatif, daya tarik, penampilan amat besar, pertimbangan dan kepemimpinan, (2) menguasai metode mengajar yang baik, (3) memiliki tingkah laku yang baik saat mengajar, dan (4) menguasai berbagai kompetensi dalam mengajar.

Widyastono (1999) berpendapat bahwa terdapat empat gugus yang erat kaitannya dengan kinerja guru, yaitu kemampuan (1) merencanakan KBM, (2) melaksanakan KBM, (3) melaksanakan hubungan antar pribadi, dan (4) mengadakan penilaian. Sedangkan Suyud (2005) mengembangkan kinerja guru profesional meliputi: (1) penguasaan bahan ajar, (2) pemahaman karakteristik siswa, (3) penguasaan pengelolaan kelas, (4) penguasaan metode dan strategi pembelajaran, (5) penguasaan evaluasi pembelajaran dan (6) kepribadian.

\section{Tinjauan Tentang Supervisi Klinis Pengawas}

Supervisi klinis yang juga disebut supervisi kelas adalah suatu bentuk bimbingan atau bantuan profesional yang diberikan kepada guru berdasarkan kebutuhan guru melalui siklus yang sistematis untuk meningkatkan proses belajar mengajar (La Sulo, Efffendi, Gojali).

Richard Waller yang dikutip oleh J.L. Bolla (1985:3) mengatakan: "Clinical Supervision may be defines as supervision focused upon the improvement of instruction by mean of systematic cycles of planning, observationand intensive intellectual analysis of actual teaching performances in the interest of rational modification".

Bantuan supervisor dipusatkan untuk meningkatkan pengajaran, dan siklus yang sistematis merupakan proses yang terdiri dari kegiatan perencanaan, observasi, dan analisis rasional yang intensif terhadap unjuk kerja mengajar yang ingin dimodifikasi untuk dikembangkan. Hoy dan Forsyth (1986:47) menyatakan: "In education the movement away from traditional supervision has been dramatic; in fact, the strong professional interest in practices designed to improve teaching classroom perforzance has been described as the clinical supervision". Dari pernyataan tersebut dapat ditarik suatu pengertian, bahwa supervisi klinis merupakan pendekatan supervisi hasil upaya reformasi terhadap supervisi yang tradisional. Sergiovani dan Starrat, dalam bukunya yang berjudul Supervision Human Perspectives mengemukakan: "...clinical supervision, which emphasis working with teacher about teaching in classroom as an activity distinct from general supervision". (1979: 309).

Sargiovani dan Starrat menegaskan bahwa supervisi klinis berbeda dengan supervisi umum. Perbedaan itu dikemukakan oleh La Sulo dkk (1995). sebagai berikut:

\section{Tabel 1. 1. Perbedaan Supervisi Klinis dengan Supervisi Non Klinis}




$\begin{array}{ll}\text { Volume } & : 05 \\ \text { Nomor } & : 02 \\ \text { Bulan } & : \text { Mei } \\ \text { Tahun } & : 2019 \\ \text { http } & : / / \text { ejurnal.pps.ung.ac.id/index.php/AKSARA/index }\end{array}$

\begin{tabular}{|l|l|l|}
\hline Aspek & Supervisi Non Klinis & Supervisi Klinis \\
\hline $\begin{array}{l}\text { a. Prakarsa dan } \\
\text { tanggungjawab }\end{array}$ & Terutama oleh supervisor & Diutamakan oleh guru \\
\hline $\begin{array}{l}\text { b. Hubungan } \\
\text { Supervisor-guru }\end{array}$ & $\begin{array}{l}\text { Hubungan atasan-bawahan } \\
\text { yang bersifat birkratis }\end{array}$ & $\begin{array}{l}\text { Hubungan kolegial yang } \\
\text { sederajat dan interaktif }\end{array}$ \\
\hline $\begin{array}{l}\text { c. Sifat supervisi } \\
\text { otoriter }\end{array}$ & $\begin{array}{l}\text { giajukan oleh } \\
\text { sesuai direktif atan } \\
\text { kebutuhannya }\end{array}$ \\
\hline $\begin{array}{l}\text { d. Sasaran supervisi } \\
\text { supervisi }\end{array}$ & $\begin{array}{l}\text { Sama-sama atau sesuai } \\
\text { dengan keinginan supervisor }\end{array}$ & $\begin{array}{l}\text { Terbatas sesuai dengan } \\
\text { kontrak }\end{array}$ \\
\hline $\begin{array}{l}\text { f. Tujuan supervisi } \\
\text { Umum dan luas }\end{array}$ & $\begin{array}{l}\text { Cimbingan analitik dan } \\
\text { deskriptif }\end{array}$ \\
\hline g. Peran supervisor & $\begin{array}{l}\text { Banyak memberi tahu dan } \\
\text { mengarahkan }\end{array}$ & $\begin{array}{l}\text { Banyak bertanya untuk } \\
\text { membantu } \\
\text { menganalisis diri guru }\end{array}$ \\
\hline h. Balikan & $\begin{array}{l}\text { Sama-sama atau atas } \\
\text { kesimpulan supervisor }\end{array}$ & $\begin{array}{l}\text { Dengan analisis dan } \\
\text { interaksi bersama atas } \\
\text { data observasi sesuai } \\
\text { kontrak }\end{array}$ \\
\hline
\end{tabular}

Dari uraian tersebut di atas dapat disimpulkan, bahwa supervisi klinis adalah suatu proses bimbingan oleh supervisor kepada guru secara kolegial dengan tujuan membantu guru dalam mengungkapkan kemampuan profesionalnya, khususnya untuk kerja mengajarnya di kelas berdasarkan observasi dan analisis data secara teliti dan objektif. Menurut J.L. Bolla (1985) istilah klinis menunjuk kepada unsur-unsur khusus sebagai berikut: (1) adanya hubungan tatap muka antara supervisor dan guru dalam proses supervisi; (2) proses supervisi difokuskan pada unjuk kerja mengajar guru di kelas; (3) data unjuk kerja mengajar diperoleh melalui observasi secara cermat; (4) data dianalisis bersama anatara supervisor dengan guru; (5) Supervisor dan guru bersama-sama menilai dan mengambil kesimpulan unjuk kerja mengajar guru; (6) Fokus observasi sesuai dengan kebutuhan dan atau permintaan guru yang bersangkutan.

Dari berbagai pendapat analisis dan uraian di atas, dapat disimpulkan, bahwa supervisi klinis adalah supervisi yang memiliki ciri-ciri esensial sebagai berikut: (1) bimbingan dari supervisor kepada guru bersifat bantuan, bukan perintah atau instruksi, sehingga prakarsa dan tanggungjawab pengembangan diri berada di tangan guru; (2) hubungan interaksi dalam proses supervisi bersifat kolegial, sehingga intim dan terbuka; (3) meskipun unjuk kerja mengajar guru di kelas bersifat luas dan terintegrasi, tetapi sasaran supervisi terbatas pada apa yang dikontrakkan; (4) sasaran supervisi diajukan oleh guru, dikaji dan disepakati bersama dalam kontrak; (5) proses supervisi klinis melalui tiga tahapan: pertemuan pendahuluan, observasi kelas, dan pertemuan balikan; (6) instrumen observasi ditentukan bersama oleh guru dan supervisor; (7) balikan yang objektif dan sepesifik diberikan dengan segera; (8) analisis dan interpretasi data observasi dilakukan bersama-sama; (9) proses supervisi bersiklus.

\section{METODE PENELITIAN}

Subjek dalam penelitian ini adalah guru SD Binaan Wilayah Kecamatan Napabalano tempat peneliti bertugas menjadi Pengawas tahun pelajaran 2013/2014. Dalam pelaksanaan 


$\begin{array}{ll}\text { Volume } & : 05 \\ \text { Nomor } & : 02 \\ \text { Bulan } & : \text { Mei } \\ \text { Tahun } & : 2019 \\ \text { http } & : / / \text { ejurnal.pps.ung.ac.id/index.php/AKSARA/index }\end{array}$

tindakan, rancangan dilakukan dalam 2 siklus yang meliputi : (a) perencanaan, (2) tindakan, (3) pengamatan, (4) refleksi.

Dalam Penelitian Tindakan Kepengawasan ini variabel yang diteliti adalah Peningkatan kinerja guru dalam proses pembelajaran melalui supervisi klinis pengawas di SD Binaan Wilayah Kecamatan Napabalano Tahun Pelajaran 2013/2014.

Variabel tersebut dapat dituliskan kembali sebagai berikut :

Variabel Harapan : Peningkatan kinerja guru dalam proses pembelajaran

Variabel Tindakan : Pembinaan melalui supervisi klinis Pengawas.

Penelitian Tindakan Kepengawasan yang dilaksanakan dalam tiga siklus dianggap sudah berhasil apabila terjadi peningkatan kinerja guru melalui pembinaan supervisi klinis Pengawas mencapai $85 \%$ guru ( sekolah yang diteliti ) telah mencapai ketuntasan dengan nilai rata rata 75. Jika peningkatan tersebut dapat dicapai pada tahap siklus 1 dan 2, maka siklus selanjutnya tidak akan dilaksanakan karena tindakan yang dilakukan sudah dinilai efektif sesuai dengan harapan dalam manajemen berbasis sekolah ( MBS ).

Penelitian ini dilakukan dengan menggunakan metode penelitian tindakan kepengawasan. Peneliti senantiasa berupaya memperoleh hasil yang optimal melalui cara dan prosedur yang dinilai paling efektif, sehingga dimungkinkan adanya tindakan yang berulang-ulang untuk meningkatkan pengelolaan kelas dalam proses belajar mengajar.

Penelitian ini diharapkan dapat membantu guru menyusun RPP pembelajaran tematik. Peneliti melaksanakan penelitian dua siklus. Dimulai siklus I sejak 1) perencanaan tindakan, 2) pelaksanaan tindakan, 3) Pengamatan, dan 4) Refleksi hingga siklus II .

\section{HASIL PENELITIAN DAN PEMBAHASAN \\ Deskripsi Siklus I}

\section{Perencanaan Tindakan}

Pada tahap ini peneliti mempersiapkan perangkat pembinaan yang terdiri dari rencana pembinaan dan alat-alat pembinaan lain yang mendukung. Selain itu juga dipersiapkan lembar pengamatan (observasi) peningkatan kinerja guru melalui supervisi klinis.

2. Pelaksanaan Tindakan

Pelaksanaan kegiatan pembinaan untuk siklus I dilaksanakan pada tanggal 03 s.d 22 Maret 2014 di SD Binaan Wilayah Kecamatan Napabalano Kabupaten Muna. Dalam hal ini peneliti bertindak sebagai Pengawas. Adapun proses pembinaan mengacu pada rencana pembinaan yang telah dipersiapkan.

3. Pengamatan (Observasi)

Pengamatan (observasi) dilaksanakan bersamaan dengan pelaksanaan pembelajaran di sekolah. Adapun proses pengamatan (observasi) dilaksanakan dengan menggunakan lembar observasi yang telah dipersiapkan, dengan tujuan untuk mengetahui tingkat keberhasilan guru dalam meningkatkan kinerjanya sesuai dengan yang telah dilakukan. Adapun data hasil penelitian pada siklus I. adalah seperti pada tabel berikut :

\section{Tabel 3.2 :}

\section{Tabel Hasil Observasi pada Siklus I}

\begin{tabular}{|l|l|l|l|l|}
\hline No & Nama Guru & Aspek Yang Diobservasi & $\neg=$ & $<\cdot-7$ \\
\hline
\end{tabular}




$\begin{array}{ll}\text { Volume } & : 05 \\ \text { Nomor } & : 02 \\ \text { Bulan } & : \text { Mei } \\ \text { Tahun } & : 2019 \\ \text { http } & : \text { //ejurnal.pps.ung.ac.id/index.php/AKSARA/index }\end{array}$

\begin{tabular}{|c|c|c|c|c|c|c|c|c|c|c|c|c|}
\hline & & \multicolumn{5}{|c|}{ Membuka Pembelajaran } & \multicolumn{4}{|c|}{ Menutup Pembelajaran } & & \\
\hline & & 1 & 2 & 3 & 4 & 5 & 6 & 7 & 8 & 9 & & \\
\hline 1 & La Nuriama, A.Ma.Pd & 3 & 3 & 4 & 3 & 2 & 3 & 3 & 4 & 2 & 27 & 60,00 \\
\hline 2 & $\begin{array}{l}\text { La Ode Insafu, } \\
\text { A.Ma.Pd }\end{array}$ & 5 & 4 & 2 & 2 & 2 & 4 & 3 & 3 & 4 & 29 & 64,44 \\
\hline 3 & Wa Ode Riamu, S.Pd & 5 & 3 & 5 & 3 & 3 & 5 & 3 & 4 & 5 & 36 & 80,00 \\
\hline 4 & La Hanisu,S.Pd & 4 & 5 & 5 & 4 & 4 & 5 & 4 & 3 & 4 & 38 & 84,44 \\
\hline 5 & Akbar, S.Pd & 3 & 4 & 5 & 3 & 2 & 3 & 3 & 4 & 3 & 30 & 66,67 \\
\hline 6 & La Sapia, S.PdI & 3 & 3 & 3 & 3 & 2 & 3 & 3 & 4 & 2 & 26 & 57,78 \\
\hline 7 & La Ili,S.Pd & 3 & 5 & 5 & 4 & 3 & 5 & 4 & 4 & 4 & 37 & 82,22 \\
\hline 8 & Tamrin, A.Ma.Pd & 3 & 3 & 4 & 3 & 2 & 3 & 3 & 4 & 2 & 27 & 60,00 \\
\hline 9 & Mariati, S.Pd & 3 & 3 & 4 & 3 & 2 & 3 & 3 & 4 & 3 & 28 & 62,22 \\
\hline 10 & $\begin{array}{l}\text { Wa Ode Ndokunu, } \\
\text { A.Ma.Pd }\end{array}$ & 3 & 3 & 3 & 3 & 2 & 3 & 3 & 4 & 2 & 26 & 57,78 \\
\hline 11 & La Ode Santiaji, S.Pd & 5 & 3 & 5 & 3 & 3 & 5 & 3 & 4 & 5 & 36 & 80,00 \\
\hline 12 & Sarmin, A,Ma & 3 & 3 & 4 & 3 & 2 & 3 & 2 & 4 & 2 & 26 & 57,78 \\
\hline 13 & Nurmiana, S.Pd & 3 & 4 & 4 & 3 & 2 & 3 & 3 & 4 & 3 & 29 & 64,44 \\
\hline 14 & Yadin Hameri, S.Pd & 4 & 3 & 5 & 4 & 4 & 4 & 4 & 3 & 4 & 35 & 77,78 \\
\hline 15 & Nuriana, A.Ma.Pd. & 3 & 3 & 3 & 3 & 1 & 3 & 3 & 4 & 2 & 25 & 55,56 \\
\hline 16 & Ladusu, A.Ma.Pd & 3 & 3 & 4 & 3 & 3 & 3 & 3 & 3 & 3 & 28 & 62,22 \\
\hline 17 & La Malihu, S.Pd & 3 & 3 & 3 & 3 & 2 & 3 & 3 & 3 & 3 & 26 & 57,78 \\
\hline 18 & Imran, S.Pd & 4 & 5 & 5 & 4 & 4 & 5 & 4 & 3 & 4 & 38 & 84,44 \\
\hline 19 & $\begin{array}{l}\text { La Ode Minasa, } \\
\text { A.Ma.Pd }\end{array}$ & 4 & 3 & 4 & 4 & 4 & 4 & 4 & 3 & 4 & 34 & 75,56 \\
\hline 20 & La Nano, A.Ma.Pd & 3 & 3 & 3 & 3 & 2 & 3 & 3 & 4 & 2 & 26 & 57,78 \\
\hline 21 & Zulkarnaen, S.Pd & 3 & 3 & 3 & 4 & 3 & 3 & 3 & 4 & 3 & 29 & 64,44 \\
\hline 22 & La Ode Muddin, S.Pd. & 3 & 5 & 5 & 4 & 4 & 4 & 4 & 4 & 4 & 37 & 82,22 \\
\hline 23 & $\begin{array}{l}\text { Moh. } \\
\text { A.Ma.Pd }\end{array}$ & 3 & 3 & 4 & 4 & 3 & 3 & 3 & 4 & 3 & 30 & 66,67 \\
\hline 24 & Wa Suhia, A.Ma.Pd & 3 & 3 & 3 & 3 & 2 & 3 & 2 & 4 & 3 & 26 & 57,78 \\
\hline 25 & Mulyati, S.Pd & 4 & 3 & 4 & 4 & 4 & 4 & 4 & 4 & 4 & 35 & 77,78 \\
\hline 26 & $\begin{array}{l}\text { Wa Ode Tupa, } \\
\text { A.Ma.Pd }\end{array}$ & 3 & 3 & 4 & 4 & 3 & 3 & 3 & 4 & 3 & 30 & 66,67 \\
\hline 27 & Sitti Hasnah & 3 & 3 & 3 & 3 & 2 & 3 & 3 & 3 & 2 & 25 & 55,56 \\
\hline Jun & & 92 & 92 & 106 & 90 & 72 & 96 & 86 & 100 & 85 & 819 & 1820 \\
\hline & & $\frac{n}{\infty}$ & $\frac{n}{\infty}$ & $\begin{array}{l}n \\
n \\
\infty\end{array}$ & $\begin{array}{l}\hat{\sigma} \\
\varnothing 0\end{array}$ & $\begin{array}{l}m \\
m \\
m\end{array}$ & $\begin{array}{l}\exists \\
\Rightarrow\end{array}$ & 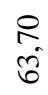 & \begin{tabular}{l}
5 \\
\multirow{t}{*}{}
\end{tabular} & $\begin{array}{l}\text { مे } \\
\text { ปู }\end{array}$ & & $\underset{⿱}{+}$ \\
\hline
\end{tabular}

\section{Keterangan :}

- $\quad$ Skor maksimum setiap aspek $=5$

- Total skor maksimum $\quad=45$

- Jumlah perolehan skor $39-45$ (Amat Baik) = Tuntas

- Jumlah perolehan skor $32-38$ (Baik) = Tuntas

- Jumlah perolehan skor 25-31 (Cukup) = Tidak Tuntas

- Jumlah perolehan skor $\geq 24$ (Kurang) = Tidak Tuntas

- Jumlah Guru yang tuntas = 9 orang

- Jumlah Guru tidak tuntas $\quad=18$ orang

- Kelompok Guru = belum tuntas

Dari tabel di atas dapat dijelaskan bahwa dengan pembinaan yang dilakukan oleh pengawas melalui supervisi klinis diperoleh nilai rata-rata guru adalah 67,40\%. Hasil tersebut menunjukkan bahwa pada siklus pertama secara kelompok guru belum meningkat kinerjanya, karena yang memperoleh nilai $\geq 32$ hanya sebesar $33,34 \%$ atau ada 9 orang guru dari 27 guru yang tuntas, hasil ini tentu lebih kecil dari prosentase ketuntasan yang dikehendaki yaitu sebesar $85 \%$. Hal ini disebabkan karena banyak guru yang belum memiliki kemampuan membuka dan menutup pembelajaran. 


$\begin{array}{ll}\text { Volume } & : 05 \\ \text { Nomor } & : 02 \\ \text { Bulan } & : \text { Mei } \\ \text { Tahun } & : 2019 \\ \text { http } & : \text { //ejurnal.pps.ung.ac.id/index.php/AKSARA/index }\end{array}$

4. Refleksi

Dalam pelaksanaan kegiatan pembinaan diperoleh informasi dari hasil pengamatan sebagai berikut:

(1) Pengawas masih kurang teliti dalam melakukan pembinaan

(2) Pengawas masih kurang baik dalam pemanfaatan waktu

(3) Pengawas masih kurang konsentrasi dalam melakukan pembinaan, karena ada tugas lain yang harus dikerjakan.

5. Revisi Rancangan

Pelaksanaan kegiatan pembinaan pada siklus I ini masih terdapat kekurangan, sehingga perlu adanya revisi untuk dilakukan pada siklus berikutnya.

Pengawas perlu lebih terampil dalam memotivasi guru dan lebih jelas dalam menyampaikan tujuan pembinaan, dimana guru diajak untuk terlibat langsung dalam setiap kegiatan yang akan dilakukan.

Pengawas perlu mendistribusikan waktu secara baik dengan menambahkan informasiinformasi yang dirasa perlu dan memberi catatan

Pengawas harus lebih terampil dan bersemangat dalam memotivasi guru sehingga kinerjanya lebih meningkat.

\section{Pembahasan Hasil Penelitian}

1. Ketuntasan Hasil Pembinaan Kinerja Guru

Melalui hasil penelitian ini menunjukkan bahwa pembinaan melalui supervisi klinis oleh Pengawas memiliki dampak positif dalam meningkatkan kinerja guru, hal ini dapat dilihat dari semakin mantapnya pemahaman guru terhadap pembinaan yang disampaikan Pengawas (Kinerja guru meningkat dari siklus I, dan II) yaitu masing-masing 67,40\%;86,50\%. Pada siklus III kinerja guru secara kelompok dikatakan tuntas.

2. Kemampuan Pengawas dalam meningkatkan kinerja guru

Berdasarkan analisis data, diperoleh aktivitas guru dalam meningkatkan kinerjanya dalam setiap siklus mengalami peningkatan. Hal ini berdampak positif terhadap peningkatan capaian mutu sekolah yaitu dapat ditunjukkan dengan meningkatnya nilai rata-rata guru pada setiap siklus yang terus mengalami peningkatan.

3. Aktivitas Pengawas dan guru dalam pembinaan melalui supervisi klinis;

Berdasarkan analisis data, diperoleh aktivitas guru yang paling dominan dalam kegiatan supervisi klinis adalah bekerja dengan menggunakan alat/media, mendengarkan/memperhatikan penjelasan Pengawas, dan diskusi antar guru dan dengan Pengawas. Jadi dapat dikatakan bahwa aktivitas guru dapat dikategorikan aktif.

Sedangkan untuk aktivitas Pengawas selama pembinaan telah melaksanakan langkahlangkah metode pembinaan melalui supervisi klinis dengan baik. Hal ini terlihat dari aktivitas pengawas yang muncul diantaranya aktivitas membuat dan merencanakan program pembelajaran, melaksanakan, memberi umpan balik/evaluasi/tanya jawab di mana prosentase untuk aktivitas di atas cukup besar.

\section{PENUTUP}

Berdasarkan analisis hasil penelitian dan diskusi dapat disimpulkan sebagai berikut: 


$\begin{array}{ll}\text { Volume } & : 05 \\ \text { Nomor } & : 02 \\ \text { Bulan } & : \text { Mei } \\ \text { Tahun } & : 2019 \\ \text { http } & : / / \text { ejurnal.pps.ung.ac.id/index.php/AKSARA/index }\end{array}$

Pembinaan Pengawas dalam upaya meningkatkan kinerja guru melalui supervisi klinis menunjukan peningkatan pada tiap-tiap siklus. Aktivitas dalam kegiatan pembinaan menunjukkan bahwa seluruh guru dapat meningkatkan kinerjanya dengan baik dalam setiap aspek. Peningkatan kinerja guru oleh Pengawas melalui supervisi klinis ini menunjukkan peningkatan pada tiap-tiap siklusnya. Aktivitas Pengawas menunjukkan bahwa kegiatan pembinaan melalui supervisi klinis bermanfaat dan dapat membantu guru untuk lebih mudah memahami konsep peran dan fungsi guru sehingga kinerja guru dapat meningkat.

\section{DAFTAR PUSTAKA}

Acheson, K. A., \& Gall, M. D. (1997). Techniques in the clinical supervisionof the teachers: Preservice and inservice applications (4th ed.). White Palins, NY: Longman.

Arends Richard I. (2007). Learning to Teach. Seventh edition. New York: McGraw Hill Companies.

Bellon, J. J., \& Bellon,E. C. (1982). Classroom supervision and instructional improvement : A synergetic process (2nd ed.). Dubuque, IA: Kendall/Hunt.

Burhanudin, 2007. Pengorganisasian Sekolah. Bahan Diktlat Manajemen Pendidikan. Jakarta: Dittendik Ditjen Mutendik, DepDikpora.

Cogan , M. (1937). Clinical supervision. Boston : Houghton-Mifflin.

Costa, A. L., \& Garmston, R. J. (1994). Cognitive coaching: A foundation for renaissance schools. Norwood, MA: Christopher-Gordon.

DepDikpora RI,2003 Undang Undang No 20 Tentang Sistem Pendidikan Nasional.Jakarta : depDikpora ,2005 Undang No 14 Tentang Guru dan Dosen.Jakarta : depiknas.

Dirjen PMPTK,2007.Peraturan Menteri No 12 Tentang Standar Kompetensi Pengawas.Jakarta: Dirjen PMTK DepDikpora.

Dirjen PMPTK,2009.Bahan Belajar Mandiri Kelompok Kerja Pengawas.Dimensi Supervisi Akademis.Jakarta : Dirjen PMTK depDikpora.

Direktorat PLP Depdikpora. 2005. Manajemen Peningkatan Mutu Berbasis Sekolah. Jakarta: Dikpora.

Glatthorn, A. A. (1990). Supervisory leadership: Introdution to instructional supervision. New York: HarperCollins.

Glatthorn A. A. (1984). Differentiated supervision. Alexandria, V A: Association for Supervision and Curriculum.

Glickman, C. D. (1990). Supervision of instruction: A developmet approach (2nd ed.). Boston: Allyn and Bacon. Supervisi Akademik-KKPS

Glickman, C. D. (1981). Developmental supervision : Altenative practices for helping teachers. New York: Holt, Rinehart and Winston.

Goldhammer, R. (1969). Clinical supervision: Special methods for the supervision of teachers. New York: Hlot, Rinehart and Winston.

Harris, B. M. (1975). Supervisory behavior in education (2nded.). Englewood Cliffs, NJ: Prentice-Hall. 